\title{
Clinical practice guidelines for radiofrequency ablation of benign thyroid nodules: a systematic review
}

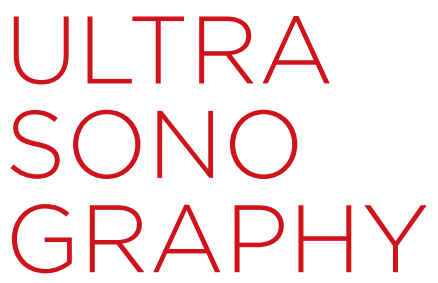

Min Kyoung Lee ${ }^{1,2}$, Jung Hwan Baek', Chong Hyun Suh', Sae Rom Chung', Young Jun Choi ${ }^{1}$, Jeong Hyun Lee', Eun Ju $\mathrm{Ha}^{3}$, Dong Gyu $\mathrm{Na}^{4,5}$

1 Department of Radiology and Research Institute of Radiology, Asan Medical Center, University of Ulsan College of Medicine, Seoul; '2Department of Radiology, Yeouido St. Mary's Hospital, College of Medicine, The Catholic University of Korea, Seoul; ${ }^{3}$ Department of Radiology, Ajou University School of Medicine, Suwon; ${ }^{4}$ Department of Radiology, GangNeung Asan Hospital, Gangneung; ${ }^{5}$ Department of Radiology, Human Medical Imaging and Intervention Center, Seoul, Korea

Purpose: Thermal ablation is a novel treatment alternative for benign thyroid nodules, and one of the most promising thermal ablation techniques is radiofrequency ablation (RFA). Considering the increasing use of thyroid RFA, some scientific societies have proposed clinical practice guidelines. We systemically reviewed and compared these guidelines for thyroid RFA to identify a standard treatment strategy that represents the positions of most societies.

Methods: We searched the MEDLINE and EMBASE databases for studies with human participants that were published in English between January 1, 2000 and August 2, 2019. Studies containing clinical practice guidelines for the RFA of benign thyroid nodules were included. We extracted data regarding indications, pre- and post-procedural evaluations, treatment techniques, and the need to obtain informed consent.

Results: Of the 83 studies found, four studies were included, and one study was added after searching the bibliographies of those articles. The five included studies were guidelines developed by the Korean Society of Thyroid Radiology, a group of experts from Italian scientific societies, the Italian Working Group on Minimally Invasive Treatments of the Thyroid, the United Kingdom's National Institute for Health and Clinical Excellence, and a group of four professional Austrian thyroid associations. Indications, pre- and post-procedural evaluations, and techniques were similar across studies; however, differences in each of these categories were found.

Conclusion: While the reviewed guidelines are similar with regard to major categories, international guidelines for the RFA of benign thyroid nodules should be established in the future.

Keywords: Thyroid; Ultrasound; Radiofrequency ablation; Benign thyroid nodules;

Recurrent thyroid cancers

How to cite this article:

Lee MK, Baek JH, Suh CH, Chung SR, Choi YJ, Lee JH, et al. Clinical practice guidelines for radiofrequency ablation of benign thyroid nodules: a systematic review. Ultrasonography 2021 Apr;40(2):256-264. 


\section{Introduction}

Thermal ablation is a promising alternative to surgery for the treatment of benign thyroid nodules [1-5]. Of the various thermal ablation techniques, radiofrequency ablation (RFA) is one of the most popular treatment modalities for benign thyroid nodules [6-8]. Previous studies $[2,9-11]$ have demonstrated that RFA is relatively safe and effective, with an acceptable complication rate. International societies have established recommendations and guidelines for the RFA of thyroid nodules. However, the existence of several differences among the numerous sets of practice guidelines may cause confusion among practitioners. An understanding of these differences may help operators in different countries to improve the use of thyroid RFA in their daily practice.

Therefore, we aimed to systematically review and compare the available clinical practice guidelines, opinions, and recommendations for the standardization of thyroid RFA.

\section{Materials and Methods}

This systematic review was performed in accordance with the Preferred Reporting Items for Systematic Reviews and MetaAnalyses statement [12].

\section{Literature Search}

A systematic literature search of the MEDLINE and EMBASE international databases was performed using the following keywords: ("thyroid" AND ("radiofrequency ablation" OR "RF ablation" OR "RFA") AND ("guideline" OR "recommendation" OR "opinion" OR "statement")). Our search was limited to studies with human participants that were published in English between January 1, 2000 and August 2, 2019. To expand the search, the bibliographies of the studies were screened to identify other appropriate articles [13]. Two radiologists (M.K.L. and C.H.S.), each with 5 years of experience, independently searched the literature and selected appropriate studies for review. If the two radiologists could not reach a consensus, a third radiologist (J.H.B., with 25 years of experience) contributed to the review to help make a final decision. The reviewers were not blinded to authors, institutions, journals, or interventions while selecting studies or extracting data.

\section{Inclusion Criteria}

We included studies or subsets of studies that satisfied the following criteria: (1) population and intervention: individuals with benign thyroid nodules and image-guided RFA, respectively; (2) study design: clinical practice guidelines (opinion statement, recommendations, or guidelines); and (3) outcomes: indications, pre- and post-procedural evaluations, techniques, and the need to obtain informed consent.

\section{Exclusion Criteria}

Studies or subsets of studies were eliminated based on the following exclusion criteria: (1) case reports or case series, editorials, letters, or conference abstracts; (2) studies outside the field of interest; and (3) studies not dealing with guidelines or recommendations for RFA.

\section{Data Extraction}

We extracted the following data from the selected studies using standardized data forms: (1) study characteristics (authors, year of publication, and affiliation); (2) indications (nonfunctioning benign thyroid nodule, autonomously functioning thyroid nodule (AFTN), and additional treatment); (3) pre- and post-procedural evaluations (imaging technique, symptom and cosmetic scores, laboratory findings, and others); (4) RFA technique (local anesthesia, needle insertion technique, moving-shot technique, and advanced techniques); and (5) the need to obtain informed consent. The data were extracted by one reviewer (M.K.L.), and two separate reviewers (E.J.H. and J.H.B.) checked the accuracy of the extracted data.

\section{Comparison of the Thyroid RFA Guidelines of International Societies}

We compared the sets of practice guidelines with regard to indications, pre- and post-procedural evaluations, techniques, and the need to obtain informed consent. The terminology used in this review was based on recent recommendations [14].

\section{Results}

\section{Literature Search}

Fig. 1 shows the process of study selection. Using the MEDLINE and EMBASE databases, we identified 83 studies, eight of which were eliminated as duplicates. Among the resulting 75 studies, 63 articles were excluded after review of the titles and abstracts. One study [13] was added after searching the bibliographies of these articles. After full-text review, eight additional studies were excluded either because they were not related to the field of interest $(n=2)$ or because they did not include new guidelines or recommendations $(n=6)$. After all exclusions, we included five studies for further review and comparison.

\section{Characteristics of the Included Studies}

Table 1 presents the characteristics of the five included studies in detail. These studies constitute sets of practice guidelines developed by the Korean Society of Thyroid Radiology (KSThR), a group of 


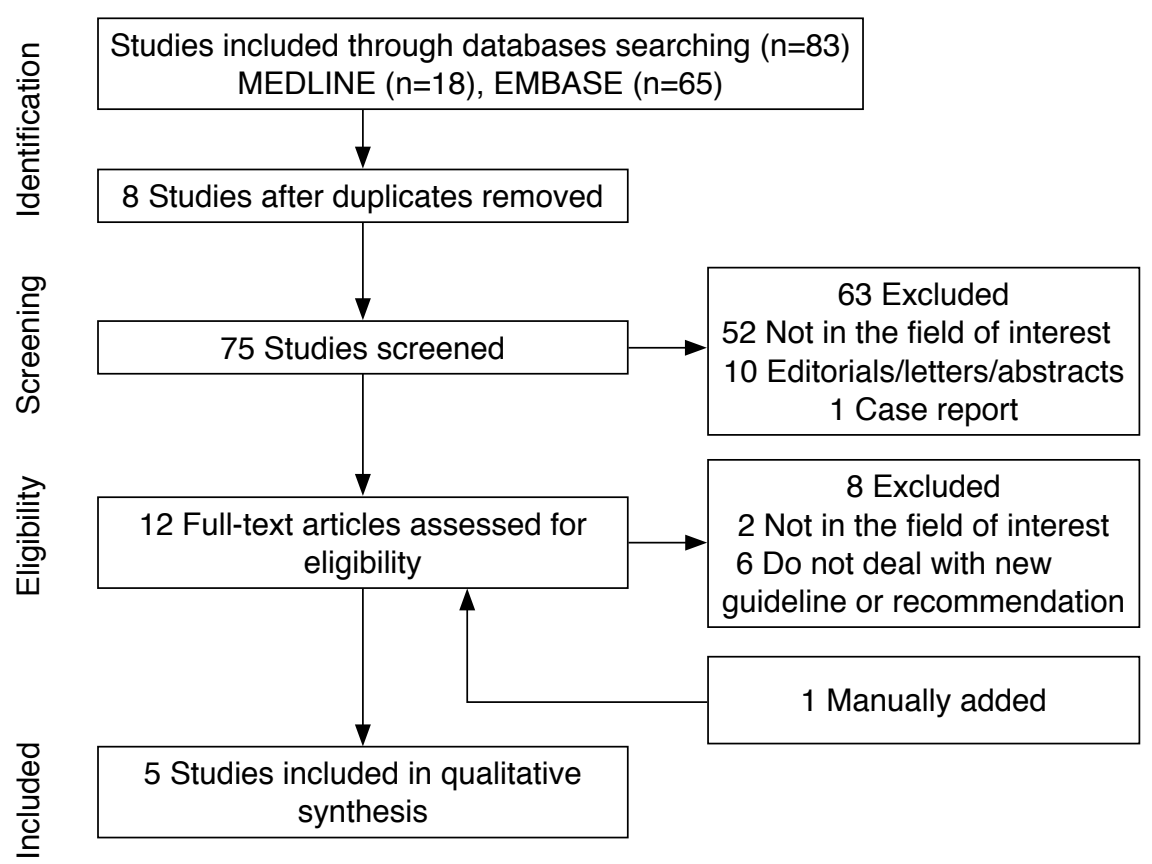

Fig. 1. Flow diagram of the study selection process.

Table 1. Characteristics of the included studies

\begin{tabular}{|c|c|c|c|}
\hline & $\begin{array}{c}\text { International society or } \\
\text { societies }\end{array}$ & $\begin{array}{c}\text { Year of } \\
\text { publication }\end{array}$ & Study \\
\hline Korea & KSThR & 2018 & Kim et al. [14] \\
\hline \multirow[t]{2}{*}{ Italy } & Italian scientific societies & 2015 & $\begin{array}{l}\text { Garberoglio et } \\
\text { al. [16] }\end{array}$ \\
\hline & MITT & 2019 & Papini et al. [15] \\
\hline $\begin{array}{l}\text { United } \\
\text { Kingdom }\end{array}$ & NICE & 2016 & NA \\
\hline Austria & $\begin{array}{l}\text { Austrian Thyroid Association, } \\
\text { Austrian Endocrine Society, } \\
\text { Surgical Endocrinology Working } \\
\text { Group of the Austrian Surgical } \\
\text { Society, and Austrian Society of } \\
\text { Nuclear Medicine }\end{array}$ & 2020 & $\begin{array}{l}\text { Dobnig et al. } \\
\text { [17] }\end{array}$ \\
\hline
\end{tabular}

KSThR, Korean Society of Thyroid Radiology; MITT, Italian Working Group on Minimally Invasive Treatments of the Thyroid; NICE, National Institute for Health and Clinical Excellence in the United Kingdom; NA, not applicable.

${ }^{a)}$ The Italian scientific societies include the Società Italiana di Ultrasonologia in Medicina e Biologia, the Società Italiana di Endocrinologia, the Associazione Medici Endocrinologi, the Società Italiana di Radiologia Medica, the Club delle Unità di Endocrinochirurgia Italiane, the Società Italiana di Chirurgia, and the Associazione Italiana di Medicina Nucleare.

experts from Italian scientific societies, the Italian Working Group on Minimally Invasive Treatments of the Thyroid, the United Kingdom's National Institute for Health and Clinical Excellence (NICE), and a group of four Austrian professional thyroid associations [13-17].

The KSThR, an organization of thyroid radiologists in Korea that is primarily involved in the diagnosis and treatment of thyroid nodules, proposed initial recommendations for thyroid RFA in 2009 [6]. Since then, several relevant studies have been published, and updates have been made in light of additional evidence regarding thyroid RFA. In response to the growing body of scientific research in this area, the KSThR revised its recommendations for thyroid RFA in 2012 and 2018. The revised recommendations cover a wide range of subjects including indications, pre-procedural evaluations, procedural techniques, monitoring and follow-up, efficacy, and safety $[2,14,18]$.

In 2015, a group of experts from Italian societies published the first Italian opinion statement on the indications for thyroid RFA [16]. In 2018, the Italian Working Group on Minimally Invasive Treatments of the Thyroid proposed the Delphi-based consensus statement for image-guided thyroid ablation [15]. We included these two articles in this systematic review $[15,16]$.

In 2019, four professional Austrian thyroid associations Austrian Thyroid Association, Austrian Society for Nuclear Medicine and Molecular Imaging, Austrian Society for Endocrinology and Metabolism, and Surgical Endocrinology Working Group of the Austrian Surgical Society published a joint interdisciplinary statement on the RFA of thyroid nodules [17]. They aimed to use these guidelines for thyroid RFA training, execution, and quality control, while providing pre- and post-interventional standards of care in Austria.

In 2016, the NICE, an executive non-departmental public body of the Department of Health in the United Kingdom [19], also published guidance for the RFA of benign thyroid nodules. They prepared an overview of the evidence-based recommendations 
developed by independent committees and established national guidelines and suggestions to improve health and social care. These guidelines were based on a review of medical articles and expert opinions and have been endorsed by Healthcare Improvement Scotland, a Scottish governmental healthcare organization. In 2016, the NICE published guidance regarding RFA for the treatment of benign thyroid nodules [13]. We manually added these NICE guidelines to a summary document in this systematic review.

\section{Indications}

Table 2 shows the similarities and differences among the guidelines with regard to indications. All guidelines [13-17] recommend RFA for patients with benign thyroid nodules who are concerned about symptoms and/or cosmetic problems. Although most benign thyroid nodules are asymptomatic, large nodules can cause compressive symptoms, including dysphasia, throat discomfort, foreign body sensation, pain, and cough, as well as cosmetic problems [20]. Therefore, the purpose of RFA is to relieve these symptoms and cosmetic issues. A symptom score is recorded by the patient using a 10-cm visual analog scale (grade 0 to 10) [20,21], and a cosmetic score is measured by a physician according to the following grades: 1 , no palpable mass; 2, a palpable mass without cosmetic problems; 3 , a cosmetic problem only during swallowing; and 4 , a nodule that is visible with the naked eye $[20,21]$.

Regarding nodule size, neither the NICE nor the Austrian societies

Table 2. Indications for RFA

\begin{tabular}{|c|c|c|c|c|}
\hline Indication & Korea & Italy & Austria & $\begin{array}{c}\text { United } \\
\text { Kingdom }\end{array}$ \\
\hline $\begin{array}{l}\text { Symptoms or cosmetic } \\
\text { problems }\end{array}$ & Y & Y & Y & $Y$ \\
\hline AFTN (toxic or pre-toxic) & Y & $Y^{a)}$ & $Y^{b)}$ & NA \\
\hline \multicolumn{5}{|l|}{$\begin{array}{l}\text { Cytopathologic } \\
\text { confirmationc) }^{\text {con }}\end{array}$} \\
\hline Two benign results & Y & Y & Y & Y \\
\hline One benign result & $\begin{array}{c}\text { K-TIRADS } 2^{\text {d) }} \\
\text { or AFTN }\end{array}$ & $\begin{array}{c}\text { EU-TIRADS 2, } 3^{\mathrm{e})} \\
\text { or AFTN }\end{array}$ & NA & NA \\
\hline Additional RFA & Y & Y & NA & NA \\
\hline
\end{tabular}

RFA, radiofrequency ablation; $Y$, recommended; AFTN, autonomously functioning thyroid nodule; NA, not applicable; K-TIRADS, Korean Thyroid Imaging Reporting and Data System; EU-TIRADS, European Thyroid Imaging Reporting and Data System; KSThR, Korean Society of Thyroid Radiology.

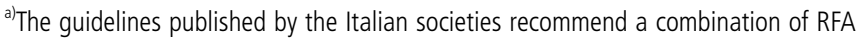

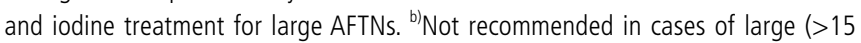
$\mathrm{mL}$ ) or multifocal AFTNs. ${ }^{\mathrm{c} A l l}$ societies recommended using fine-needle aspiration for cytopathologic confirmation. Only the KSThR recommended core-needle biopsy

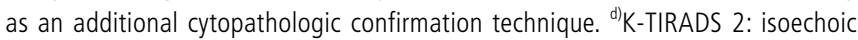
spongiform nodule or partially cystic nodule with intracystic comet tail artifact. ${ }^{\text {e) }} \mathrm{EU}$ TIRADS 2, 3: entire spongiform or ovoid and smooth isoechoic or hyperechoic nodule without highly suspicious ultrasound features. provide any criteria for treatment $[13,17]$. The Italian scientific societies recommend RFA for large nodules (volume $>20 \mathrm{~mL}$ ) with local symptoms or cosmetic problems [16]. Although the KSThR guidelines are primarily focused on symptoms and cosmetic problems, they suggest that a continuously growing nodule larger than $2 \mathrm{~cm}$ can be considered for RFA [14]. Regarding AFTNs, all societies [14-17] except the NICE recommend RFA as a therapeutic option. However, the Austrian societies [17] do not recommend RFA for larger (>15 mL) or multifocal AFTNs; the Italian societies [16] share that recommendation, while also advising radioiodine treatment for large AFTNs (volume $>20 \mathrm{~mL}$ ).

All societies [13-17] recommend cytopathologically confirming the benignity of the lesion at least twice using fine-needle aspiration (FNA) or core-needle biopsy (CNB) [22,23]. According to the KSThR [14], a single diagnosis of benignity is permitted in cases of thyroid nodules demonstrating highly specific benign ultrasound (US) features (that is, isoechoic spongiform nodules or partially cystic nodules with intracystic comet tail artifacts) and in cases of AFTN. Similarly, the Italian societies $[15,16]$ accept a single cytopathology result in nodules demonstrating benign features or low-risk presentations on US examination (that is, entire spongiform or ovoid and smooth isoechoic/hyperechoic nodules without highly suspicious US features) or in cases of AFTN. The KSThR and the group of Italian societies recommend ethanol ablation as the first line of treatment for a pure cyst or a predominantly cystic nodule [14-16,24]. However, the KSThR and Italian MITT group recommend RFA in patients with symptoms that are incompletely resolved or that recur after ethanol ablation $[14,15,25]$.

Additional treatment is proposed by the KSThR and the Italian societies $[14,15]$ in cases when the treated nodule shows marginal regrowth, a volume reduction of $<50 \%$, or an incomplete resolution or relapse of symptoms or cosmetic problems $[14,15]$.

\section{Pre-procedural Evaluation}

Table 3 shows recommendations for pre-procedural evaluations for RFA. All societies [13-17] recommend careful evaluation of US features before treatment. US evaluation is important to characterize the nodule size, composition, vascularity, and presence or absence of cervical lymph nodes, as well as the relationships between critical structures and the thyroid nodule [13-17]. RFA of thyroid nodules with suspicious US features should be performed carefully $[22,26]$. Even if the thyroid nodule was initially diagnosed as benign via FNA or CNB, the rate of malignancy is relatively high in thyroid nodules with suspicious US features [22]. The KSThR and the Austrian societies $[14,17]$ recommend repeat US-guided biopsy of thyroid nodules with suspicious US features, and the Italian and Austrian societies recommend performing repeat FNA for fast-growing 
Table 3. Consensus recommendations from international societies for pre- and post-procedural checklists

\begin{tabular}{|c|c|c|c|c|}
\hline Checklist & Korea & Italy & Austria & United Kingdom \\
\hline \multicolumn{5}{|l|}{ Pre-procedural } \\
\hline US findings & Y & Y & Y & Y \\
\hline Symptom and cosmetic scores & Y & Y & Y & Y \\
\hline Laboratory findings & CBC, coagulation test, and TFT & TFT & TFT & NA \\
\hline \multicolumn{5}{|l|}{ Other imaging } \\
\hline $\mathrm{CT}$ & Selective ${ }^{a)}$ & NA & NA & NA \\
\hline Thyroid scan ${ }^{b)}$ & Y & NA & Y & NA \\
\hline US findings & Size, echogenicity, internal vascularity & Size & $\begin{array}{c}\text { Size, echogenicity, internal } \\
\text { vascularity, and cervical lymph node }\end{array}$ & \\
\hline Symptom and cosmetic scores & Y & Y & Y & Y \\
\hline \multirow[t]{2}{*}{ Laboratory findings } & Y & Y & Y & NA \\
\hline & TFT on AFTN & & TFT and autoantibody & \\
\hline \multicolumn{5}{|l|}{ Other imaging } \\
\hline $\mathrm{CT}$ & Selective $^{\mathrm{a})}$ & NA & NA & NA \\
\hline Thyroid scan ${ }^{\text {b) }}$ & Y & NA & Y & NA \\
\hline Laryngoscopy & NA & NA & Y & NA \\
\hline
\end{tabular}

US, ultrasonography; Y, recommended; CBC, complete blood count; TFT, thyroid function test (thyrotropin, triiodothyronine, and free thyroxine); NA, not applicable; CT, computed tomography; AFTN, autonomously functioning thyroid nodule.

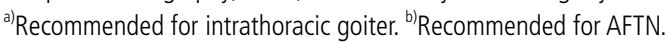

thyroid nodules [15-17]. A detailed pre-procedural evaluation should therefore be performed in cases of thyroid nodules with suspicious US features. If suspicious findings, including extrathyroidal extension or indeterminate lymph nodes, are found, additional computed tomography or repeat biopsy should be performed to rule out potential malignancy. The rate of thyroid nodule malignancy after two benign confirmations is very low, so at that point, the nodule may be considered benign [27]. Three orthogonal diameters and target nodule volumes should be measured to establish a baseline set of measurements. Furthermore, evaluations of symptom and cosmetic scores are recommended by all societies.

All societies except the NICE [14-17] recommend laboratory tests, including a complete blood count, a coagulation test (bleeding time, prothrombin time, and activated partial thromboplastin time), and a thyroid function test (thyrotropin, triiodothyronine, and free thyroxine). Autoantibodies (anti-thyroid peroxidase antibody and anti-thyroglobulin antibody) can be selectively evaluated, since patients with elevated autoantibody levels can develop subclinical hypothyroidism after RFA [9]. Overt hypothyroidism should be managed by hormone replacement therapy, and hyperthyroidism should be further evaluated using ${ }^{99 \mathrm{~m}} \mathrm{Tc}$ pertechnetate or an ${ }^{123} \mathrm{I}$ thyroid scan $[14,17]$. In patients with AFTN, it is important to perform a thyroid function test to establish a baseline measurement for use in evaluating treatment outcomes $[14,15]$.

Other imaging techniques, including computed tomography and magnetic resonance imaging, can be used to evaluate the intrathoracic extension of large thyroid nodules $[14,17]$. The group of Austrian societies [17] recommends laryngoscopic examination for all patients before and after RFA to ensure vocal cord mobility.

Both the KSThR and the Austrian reports mention patients with a bleeding tendency. The KSThR guidelines mention the pre-procedural process for patients who were previously prescribed anticoagulants or antiplatelet drugs [14]. Patients with medications associated with a bleeding tendency should be instructed to discontinue medications 7-10 days prior to RFA for aspirin or clopidogrel, 3-5 days prior for warfarin, and 4-6 hours prior for heparin [28]. The patient 
can resume taking the drugs 2-6 hours after RFA for heparin, the night after RFA for warfarin, and the day after RFA for aspirin or clopidogrel [28]. The Austrian guidelines [17] only mention the preprocedural process for patients with a bleeding tendency in the contraindication section.

\section{Techniques}

Table 4 shows techniques recommended for thyroid RFA. Prior to ablation, all societies recommend local rather than general anesthesia for pain control [13-16]. The report published by the Austrian societies [17] mentions that a few centers allow the intravenous administration of analgesics and sedatives; however, concerns have been raised about the delayed detection of complications. To reduce pain during RFA, perithyroidal lidocaine injection is considered crucial, since sensory nerves typically exist around the thyroid capsule. The electrode should be inserted just superficial to the thyroid isthmus and then advanced into the thyroid gland through the isthmus [29].

Regarding the devices used, the KSThR recommends that a thyroid-dedicated monopolar (18- or 19-G) internally cooled electrode be used as a standard for RFA. A bipolar electrode may be recommended for patients with electrical devices (such as cardiac pacemakers) or for pregnant women [30]. However, the ablation zone tends to be ellipsoidal and smaller when a bipolar electrode is used than when a monopolar electrode is used $[29,31]$. The guidelines published by the Austrian societies recommend the use of a thyroid-dedicated monopolar electrode; however, they introduce the use of a bipolar electrode with the "multiple overlapping shot" technique [17]. Although early results using the bipolar technique appear promising, long-term outcomes and the systematic treatment of larger patient populations with different nodal characteristics are necessary [31-33].

All societies except the NICE recommend the transisthmic approach and the moving-shot technique as basic techniques [1417]. The transisthmic approach involves the insertion of the electrode

Table 4. RFA techniques

\begin{tabular}{|c|c|c|c|c|}
\hline Technique & Korea & Italy & Austria & United Kingdom \\
\hline Local anesthesia & Y & Y & $Y^{a)}$ & Y \\
\hline Transisthmic approach & Y & Y & Y & NA \\
\hline Moving-shot technique & Y & Y & Y & NA \\
\hline \multicolumn{5}{|l|}{ Advanced techniques } \\
\hline Vascular ablation & Y & NA & NA & NA \\
\hline Hydrodissection & Y & NA & NA & NA \\
\hline
\end{tabular}

needle via the thyroid isthmus in a medial-to-lateral direction [29], while the moving-shot technique refers to the unit-by-unit ablation of thyroid nodules accomplished by moving the electrode. Since the thyroid nodule is ellipsoidal in shape and exophytic from the thyroid gland, nodules are divided into multiple small ablation units and ablated safely using the moving-shot technique $[29,34]$.

With regard to the procedure, the electrode is inserted to the deepest portion of the nodule and is pulled back in the superficial direction. The procedure is repeated in the adjacent areas until the entire nodule displays echogenic changes $[29,34]$. The electrode tip should be monitored continuously during RFA to prevent thermal damage to adjacent critical structures [29,34]. The KSThR guidelines introduce advanced techniques, including vascular ablation and hydrodissection [29]. Vascular ablation includes two different techniques: artery-first ablation and marginal venous ablation. These methods are useful to reduce the marginal recurrence of hypervascular tumors [29]. Hydrodissection is used for treating thyroid nodules adjacent to critical surrounding structures $[29,35]$. The injection of $5 \%$ dextrose water separates the thyroid nodules from the critical surrounding structures and provides a thermal barrier [36].

\section{Post-procedural Evaluation}

Table 3 shows the post-procedural checklist after RFA. All societies suggest a similar post-procedural evaluation; however, minor differences exist in the evaluation of autoantibodies and the vocal cord examination. Changes in US findings-including nodule size, volume, and vascularity-as well as symptom and cosmetic scores require further study to assess the treatment efficacy and clinical outcomes after RFA. Additional treatment is recommended if the nodule has a viable vascular portion or if an increase in nodule volume is observed [37]. The treatment efficacy is measured by the volume reduction rate (VRR) and changes in the symptom and cosmetic scores. The VRR is measured as follows: ([Initial volumeFinal volume] $\times 100$ )/Initial volume). In the KSThR guidelines, a VRR of less than $50 \%$ is an indication for additional RFA [14]. Regarding AFTNs, the evaluation of changes in thyroid function test results is necessary to assess the therapeutic response, and a thyroid scan may also facilitate the assessment of the treatment response $[34,37-40]$

\section{Informed Consent}

Regarding informed consent, the KSThR provides a checklist of information that should be given to patients before RFA (Table 5) [14]. The Austrian societies also mention the need for informed consent, but they do not provide a detailed breakdown of information [17]. 
Table 5. Information to provide patients for informed consent ${ }^{\text {a) }}$

1. Ablated thyroid nodules decrease in size gradually over several months to years.

2. Number of expected treatment sessions

3. Possibility of regrowth of ablated nodule and need for additional ablation

4. Patients may experience pain during the ablation. For that reason, local and possibly systemic anesthetic agents may be used during and after the procedure.

5. Complications and side effects

6. Physician takes patients' past medical history, including details on surgery and medication

7. Further observation, admission, or medication may be required after RFA, depending on the patient's condition.

Adapted form Kim et al. Korean J Radiol 2018;19:632-655 [14], according to Creactive Commons license.

RFA, radiofrequency ablation; KSThR, Korean Society of Thyroid Radiology.

a)These details were recommended by the KSThR. The group of Austrian societies simply mentioned the need to obtain informed consent from patients.

\section{Discussion}

The current systematic review demonstrates the similarities and differences between the analyzed guidelines for RFA of the thyroid gland. Differences in these guidelines may lead to confusion with regard to patient care strategies. Therefore, the awareness and understanding of these differences are important to establish a unified opinion. In the future, we should share our opinions through conferences and multinational research to reduce these differences.

Although international societies recommend similar indications for RFA, these guidelines have several minor differences. All societies recommend performing RFA in patients with symptoms or cosmetic problems, and they also recommend RFA for thyroid nodules that have been confirmed to be cytopathologically benign at least twice via FNA or CNB. The KSThR and Italian societies guidelines additionally state that a single benign diagnosis can be allowed for thyroid nodules with highly specific benign US features and for AFTNs [14-16]. All of the societies except the NICE recommend performing RFA for AFTNs; however, the criteria regarding nodule size differ among the societies. The Italian scientific and Austrian societies $[16,17]$ do not recommend RFA for large AFTNs, while the KSThR guidelines [14] do not include a specific size criterion. According to the KSThR [14], large AFTNs can be treated using advanced RFA techniques, since vascular ablation is effective in reducing the vascularity of AFTNs [29]. The indications for repeated RFA require further clarification; however, they are mentioned by the KSThR and the Italian societies. These groups recommend additional RFA in cases with marginal regrowth of a treated nodule, a VRR of $<50 \%$, or persistent symptoms or cosmetic problems [14-16].
The pre- and post-procedural evaluations are similar overall and lack major differences across guidelines. Both the KSThR and the group of Austrian societies mention the need to obtain informed consent for RFA $[14,17]$; however, only the KSThR provides details regarding the information that should be given to patients. The recommended RFA techniques are also similar across the guidelines. All of the societies except the NICE recommend the transisthmic approach and the moving-shot technique [14-17]. However, advanced techniques, including vascular ablation and hydrodissection, were recommended by the KSThR [14] and could be effective for treating large AFTNs [29]. To control pain, all societies recommend local anesthesia; however, only the Austrian societies permit the intravenous administration of analgesics and sedatives. Some debate exists regarding the use of sedation for thyroid RFA, given that it can delay the detection of complications.

This study has several limitations. First, while we included five guidelines, some aspects of thyroid RFA have not been clearly described in the literature. Second, we did not include other minimally invasive ablation techniques, including ethanol ablation, laser ablation, microwave ablation, and high-intensity focused US. Comparison among ablation techniques may be essential for the treatment of benign thyroid nodules.

In this systematic review, we demonstrated that all societies reported similar indications, pre- and post-procedural evaluations, and techniques with regard to thyroid RFA. However, the presence of several differences may cause confusion among RFA practitioners, so further modification and standardization should be performed to establish international guidelines.

ORCID: Min Kyoung Lee: https://orcid.org/0000-0003-3172-3159; Jung Hwan Baek: https://orcid.org/0000-0003-0480-4754; Chong Hyung Suh: https://orcid.org/00000002-4737-0530; Sae Rom Chung: https://orcid.org/0000-0003-4219-7166; Young Jun Choi: https://orcid.org/0000-0002-1481-3200; Jeong Hyun Lee: https://orcid.org/00000002-0021-4477; Eun Ju Ha: https://orcid.org/0000-0002-1234-2919; Dong Gyu Na: https://orcid.org/0000-0001-6422-1652

\section{Author Contributions}

Conceptualization: Baek JH, Lee JH. Data acquisition: Lee MK, Suh $\mathrm{CH}$, Baek JH, Ha EJ. Data analysis or interpretation: Lee MK, Baek JH, Chung SR, Choi YJ. Drafting of the manuscript: Lee MK, Baek JH, Ha EJ. Critical revision of the manuscript: Baek JH, Ha EJ. Approval of the final version of the manuscript: all authors.

\section{Conflict of Interest}

No potential conflict of interest relevant to this article was reported. 


\section{References}

1. Mauri G, Cova L, Monaco CG, Sconfienza LM, Corbetta S, Benedini $S$, et al. Benign thyroid nodules treatment using percutaneous laser ablation (PLA) and radiofrequency ablation (RFA). Int J Hyperthermia 2017;33:295-299.

2. Na DG, Lee JH, Jung SL, Kim JH, Sung JY, Shin JH, et al. Radiofrequency ablation of benign thyroid nodules and recurrent thyroid cancers: consensus statement and recommendations. Korean J Radiol 2012;13:117-125.

3. Kotewall N, Lang BH. High-intensity focused ultrasound ablation as a treatment for benign thyroid diseases: the present and future. Ultrasonography 2019;38:135-142.

4. Mauri G, Nicosia L, Della Vigna P, Varano GM, Maiettini D, Bonomo $\mathrm{G}$, et al. Percutaneous laser ablation for benign and malignant thyroid diseases. Ultrasonography 2019;38:25-36.

5. Lang BH, Wu AL. The efficacy and safety of high-intensity focused ultrasound ablation of benign thyroid nodules. Ultrasonography 2018;37:89-97.

6. Baek J, Na D, Lee J, Jung S, Sung J, Sim J. Korean Society of Thyroid Radiology recommendations for radiofrequency ablation of thyroid nodules. Seoul: Korean Society of Thyroid Radiology, 2009.

7. Baek JH, Jeong HJ, Kim YS, Kwak MS, Lee D. Radiofrequency ablation for an autonomously functioning thyroid nodule. Thyroid 2008; 18:675-676.

8. Baek JH, Lee JH, Valcavi R, Pacella CM, Rhim H, Na DG. Thermal ablation for benign thyroid nodules: radiofrequency and laser. Korean J Radiol 2011;12:525-540.

9. Baek JH, Lee JH, Sung JY, Bae JI, Kim KT, Sim J, et al. Complications encountered in the treatment of benign thyroid nodules with USguided radiofrequency ablation: a multicenter study. Radiology 2012;262:335-342.

10. Chung SR, Suh CH, Baek JH, Park HS, Choi YJ, Lee JH. Safety of radiofrequency ablation of benign thyroid nodules and recurrent thyroid cancers: a systematic review and meta-analysis. Int J Hyperthermia 2017;33:920-930.

11. Jung SL, Baek JH, Lee JH, Shong YK, Sung JY, Kim KS, et al. Efficacy and safety of radiofrequency ablation for benign thyroid nodules: a prospective multicenter study. Korean J Radiol 2018;19:167-174.

12. Liberati A, Altman DG, Tetzlaff J, Mulrow C, Gotzsche PC, Ioannidis JP, et al. The PRISMA statement for reporting systematic reviews and meta-analyses of studies that evaluate health care interventions: explanation and elaboration. PLoS Med 2009;6:e1000100.

13. National Institute for Health and Care Excellence. Ultrasound-guided percutaneous radiogrequency ablation for benign thyroid nodules. Interventional procedure guidance [IPT562] [Internet]. London: National Institute for Health and Care Excellence, 2016 [cited 2016 Jun 22]. Available from: https://www.nice.org.uk/guidance/ipg562.
14. Kim JH, Baek JH, Lim HK, Ahn HS, Baek SM, Choi YJ, et al. 2017 Thyroid radiofrequency ablation guideline: Korean Society of Thyroid Radiology. Korean J Radiol 2018;19:632-655.

15. Papini E, Pacella CM, Solbiati LA, Achille G, Barbaro D, Bernardi $S$, et al. Minimally-invasive treatments for benign thyroid nodules: a Delphi-based consensus statement from the Italian minimallyinvasive treatments of the thyroid (MITT) group. Int J Hyperthermia 2019;36:376-382.

16. Garberoglio R, Aliberti C, Appetecchia M, Attard M, Boccuzzi G, Boraso $F$, et al. Radiofrequency ablation for thyroid nodules: which indications? The first Italian opinion statement. J Ultrasound 2015;18:423-430.

17. Dobnig H, Zechmann W, Hermann M, Lehner M, Heute D, Mirzaei $S$, et al. Radiofrequency ablation of thyroid nodules: "Good Clinical Practice Recommendations" for Austria: an interdisciplinary statement from the following professional associations: Austrian Thyroid Association (OSDG), Austrian Society for Nuclear Medicine and Molecular Imaging (OGNMB), Austrian Society for Endocrinology and Metabolism (OGES), Surgical Endocrinology Working Group (ACE) of the Austrian Surgical Society (OEGCH). Wien Med Wochenschr 2020;170:6-14.

18. Kim JH, Baek JH, Lim HK, Na DG. Summary of the 2017 thyroid radiofrequency ablation guideline and comparison with the 2012 guideline. Ultrasonography 2019;38:125-134.

19. House of Commons Health Committee. National Institute for Health and Clinical Excellence: eighth report of session 2012-13. London: House of Commons Health Committee, 2013.

20. Baek JH, Kim YS, Lee D, Huh JY, Lee JH. Benign predominantly solid thyroid nodules: prospective study of efficacy of sonographically guided radiofrequency ablation versus control condition. AJR Am J Roentgenol 2010;194:1137-1142.

21. Jang SW, Baek JH, Kim JK, Sung JY, Choi H, Lim HK, et al. How to manage the patients with unsatisfactory results after ethanol ablation for thyroid nodules: role of radiofrequency ablation. Eur J Radiol 2012;81:905-910.

22. Kwak JY, Koo H, Youk JH, Kim MJ, Moon HJ, Son EJ, et al. Value of US correlation of a thyroid nodule with initially benign cytologic results. Radiology 2010;254:292-300.

23. Ha EJ, Lim HK, Yoon JH, Baek JH, Do KH, Choi M, et al. Primary imaging test and appropriate biopsy methods for thyroid nodules: guidelines by Korean Society of Radiology and national evidence-based healthcare collaborating agency. Korean J Radiol 2018; 19:623-631.

24. Park HS, Yim Y, Baek JH, Choi YJ, Shong YK, Lee JH. Ethanol ablation as a treatment strategy for benign cystic thyroid nodules: a comparison of the ethanol retention and aspiration techniques. Ultrasonography 2019;38:166-171.

25. Hahn SY, Shin JH, Na DG, Ha EJ, Ahn HS, Lim HK, et al. Ethanol ablation of the thyroid nodules: 2018 consensus statement by the 
Korean Society of Thyroid Radiology. Korean J Radiol 2019;20:609620.

26. Hahn SY, Shin JH, Oh YL. What is the ideal core number for ultrasonography-guided thyroid biopsy of cytologically inconclusive nodules? AJNR Am J Neuroradiol 2017;38:777-781.

27. Orlandi A, Puscar A, Capriata E, Fideleff H. Repeated fine-needle aspiration of the thyroid in benign nodular thyroid disease: critical evaluation of long-term follow-up. Thyroid 2005;15:274-278.

28. Kwok A, Faigel DO. Management of anticoagulation before and after gastrointestinal endoscopy. Am J Gastroenterol 2009; 104:3085-3097.

29. Park HS, Baek JH, Park AW, Chung SR, Choi YJ, Lee JH. Thyroid Radiofrequency Ablation: Updates on Innovative Devices and Techniques. Korean J Radiol 2017;18:615-623.

30. Livraghi T, Solbiati L, Meloni MF, Gazelle GS, Halpern EF, Goldberg SN. Treatment of focal liver tumors with percutaneous radiofrequency ablation: complications encountered in a multicenter study. Radiology 2003;226:441-451.

31. Kohlhase KD, Korkusuz Y, Groner D, Erbelding C, Happel C, Luboldt $W$, et al. Bipolar radiofrequency ablation of benign thyroid nodules using a multiple overlapping shot technique in a 3-month followup. Int J Hyperthermia 2016;32:511-516.

32. Li XL, Xu HX, Lu F, Yue WW, Sun LP, Bo XW, et al. Treatment efficacy and safety of ultrasound-guided percutaneous bipolar radiofrequency ablation for benign thyroid nodules. $\mathrm{Br} J$ Radiol 2016;89:20150858.

33. Korkusuz Y, Mader A, Groner D, Ahmad S, Mader OM, Grunwald F, et al. Comparison of mono- and bipolar radiofrequency ablation in benign thyroid disease. World J Surg 2017;41:2530-2537.

34. Baek JH, Ha EJ, Choi YJ, Sung JY, Kim JK, Shong YK. Radiofrequency versus ethanol ablation for treating predominantly cystic thyroid nodules: a randomized clinical trial. Korean J Radiol 2015;16:13321340.

35. Shin JH, Baek JH, Ha EJ, Lee JH. Radiofrequency ablation of thyroid nodules: basic principles and clinical application. Int J Endocrinol 2012;2012:919650.

36. Chung SR, Baek JH, Choi YJ, Lee JH. Management strategy for nerve damage during radiofrequency ablation of thyroid nodules. Int J Hyperthermia 2019;36:204-210.

37. Sung JY, Baek JH, Jung SL, Kim JH, Kim KS, Lee D, et al. Radiofrequency ablation for autonomously functioning thyroid nodules: a multicenter study. Thyroid 2015;25:112-117.

38. Bernardi S, Stacul F, Michelli A, Giudici F, Zuolo G, de Manzini N, et al. 12-month efficacy of a single radiofrequency ablation on autonomously functioning thyroid nodules. Endocrine 2017;57:402408.

39. Huh JY, Baek JH, Choi H, Kim JK, Lee JH. Symptomatic benign thyroid nodules: efficacy of additional radiofrequency ablation treatment session: prospective randomized study. Radiology 2012;263:909-916.

40. Faggiano A, Ramundo V, Assanti AP, Fonderico F, Macchia PE, Misso $C$, et al. Thyroid nodules treated with percutaneous radiofrequency thermal ablation: a comparative study. J Clin Endocrinol Metab 2012;97:4439-4445. 